\title{
Exposure to cotton dust in an experimental cardroom
}

\author{
P HAGLIND AND R RYLANDER
}

From the Department of Environmental Hygiene, University of Gothenburg, S-400 33 Gothenburg, Sweden

ABSTRACT Changes in respiratory function $\left(\mathrm{FEV}_{1}\right)$ and polymorphonuclear neutrophils (PMN) on nasal epithelium were studied in 68 students and 39 cotton mill workers in an experimental cardroom. The exposure was characterised by the vertical elutriator dust and endotoxin levels. A dose related decrease was found for $\mathrm{FEV}_{1}$ which was more pronounced in smoking workers. The thresholds for no FEV reaction were $0.58 \mathrm{mg} / \mathrm{m}^{3}$ dust and $0.17 \mu \mathrm{g} / \mathrm{m}^{3}$ endotoxin for students and $0.43 \mathrm{mg} / \mathrm{m}^{3}$ and $0.08 \mu \mathrm{g} / \mathrm{m}^{3}$ for smoking workers. The PMN increased in most of the experiments but no dose response relationship could be shown. In experiments with smoking workers or when washed cotton was carded a better correlation was obtained between $\mathrm{FEV}_{1}$ decrease and endotoxin levels than for dust levels.

Byssinosis in the cotton and flax industry is generally related to the amount of airborne dust although the causative agent is not the cotton fibre itself but a contaminant thereon. ${ }^{\prime}$ Dose response relationships have been presented by several researchers and used as the basis for standards. ${ }^{2}$

A closer relationship has been shown between chest tightness and airborne Gram-negative bacteria $^{34}$ and between the decrease in forced expiratory volume in one second $\left(\mathrm{FEV}_{1}\right)$ and the number of Gram-negative bacteria in the processed cotton. ${ }^{5}$ The effect has been related to bacterial lipopolysacchrides (endotoxin) present in the outer cell wall of Gram-negative bacteria. ${ }^{6}$ In some studies a larger reaction has been found among smokers compared with non-smokers at the same exposure levels. ${ }^{2}$

To explore further the reactions among previously unexposed subjects and cotton mill workers after exposure to cotton dust studies were undertaken in an experimental cardroom where the dust level could be varied. Workers from cotton mills and students not previously exposed to cotton dust were used as test subjects. FEV 1 was measured before and after a four hour working session which for the cotton mill workers took place on a Monday. The number of polymorphonuclear leukocytes (PMN) in the nasal secretion was determined. Information on subjective symptoms such as chest tightness and fever was obtained from questionnaires.

Received 10 January 1983.

Accepted 11 July 1983

\section{Material and methods}

The study was performed in an experimental cardroom measuring $6.4 \times 5.3 \times 2.8 \mathrm{~m}$. A carding machine without a protective cover was situated in the middle of the room and cotton laps were processed. The dust levels in the room could be varied by adjusting the ventilation.

In the experiments United States middle grade bale cotton was used. For some of the experiments washed cotton was prepared. The washing procedure consisted of flushing water over a web of cotton on a rayon manufacturing line whereafter the cotton, was dried. The maximum temperature during the process was $66^{\circ} \mathrm{C}$.

The exposure in the cardroom was determined using three vertical elutriators ${ }^{7}$ placed on different sides of the carding machine. The filters collecting respirable dust were weighed on a semimicro balance (Sartorius 2474) using an alpha-radiating source to prevent static electricity. The mean value from two or three filters was calculated and expressed as $\mathrm{mg} / \mathrm{m}^{3}$.

After weighing, the elutriator filters were shaken in $10 \mathrm{ml}$ of pyrogene free water, which was serially diluted. The amount of airborne endotoxin was determined using the Limulus amoebocyte lysate (LAL) technique. ${ }^{8}$ Then $0 \cdot 1 \mathrm{ml}$ of Limulus lysate (Cape Cod Associates) was added to $0.1 \mathrm{ml}$ portions of dilutions of dust filter water extracts. The last dilution giving a stable clot was read as the Escherichia coli endotoxin equivalent concentration. Dilutions were also prepared with commercial $E$ coli endotoxin ( $E$ coli 026-B26 Difco) to assess the 
accuracy of the LAL reference standard. These values were always found to agree closely with the stated values. The amount of endotoxin in the water extract of the dust filter was related to the amount of air drawn through the filter. The mean value from two or three filters was calculated and reported as $\mu g$ of endotoxin $/ \mathrm{m}^{3}$ of air.

Female and male cotton mill workers, with or without a history of byssinosis (grade $1 / 2$ or 1 ) according to Schilling's classification, were taken to the experimental cardroom on a Monday morning. All but one of the workers had a FEV above $80 \%$ of the predicted value ${ }^{9}$ before work.

Non-smoking university students of both sexes were used as subjects not previously exposed to cotton dust. Those with asthma or allergic symptoms were not allowed to participate. All but one of the students had a baseline $\mathrm{FEV}_{1}$ above $80 \%$ of the predicted value.9 Three experiments with 15 students entailed no exposure to cotton dust to obtain baseline values for the $\mathrm{FEV}_{1}$ change over a time period equal to the exposure time in the cardroom. The workers were divided into non-smokers and smokers. Table 1 shows the age and time of cotton dust exposure in the different groups.

Before carding, the FEV 1 was determined using a Collins survey water spirometer with a computer (Eagle One). The forced expirations were followed on an XY-recorder. The measurements were supervised by experienced technicians and calibrations were made daily. At least two and usually several more satisfactory forced expirations were obtained. The single largest $\mathrm{FEV}_{1}$ was expressed as a percentage of the predicted value. ${ }^{9}$

The subjects worked in the cardroom for about four hours after which the measurements were repeated. The difference between the percentages before and after carding was calculated for each subject.

The number of PMN on the surface of the nasal epithelium was determined by inserting a medical cotton swab into one nostril, drawing it along the nasal wall, and suspending the secretion in saline. A sample was stained and counted in a Bürker chamber. The relation between the number of PMN and the number of epithelial cells was determined

Table 1 Age and time of cotton dust exposure among students and non-smoking and smoking workers (mean and range)

\begin{tabular}{|c|c|c|c|}
\hline & \multirow{2}{*}{$\begin{array}{l}\text { Students } \\
(n=68)\end{array}$} & \multicolumn{2}{|l|}{ Workers } \\
\hline & & $\begin{array}{l}\text { Non-smoking } \\
(n=16)\end{array}$ & $\begin{array}{l}\text { Smoking } \\
(n=23)\end{array}$ \\
\hline \multirow{2}{*}{$\begin{array}{l}\text { Age (y) } \\
\text { Time of cotton dust } \\
\text { exposure }\end{array}$} & $26(18-44)$ & $49(27-63)$ & $44(22-64)$ \\
\hline & 0 & $21(7-38)$ & $18(4-42)$ \\
\hline
\end{tabular}

and the difference between values before and after carding was calculated.

Questionnaires were used to register the presence of cough, chest tightness, and mill fever at the end of the exposure and later in the evening.

For statistical analyses, Pitman's test was used in combination with a pooling procedure testing the relation between two variables while a third factor remained constant. ${ }^{10}$ In certain tests the MannWhitney U-test was used. All tests were two-tailed and $\mathrm{p}<0.05$ was accepted as the level. of significance. To describe the relation between FEV, changes and dust or endotoxin exposures, linear regressions were calculated using natural logarithmic transformation of the dose as the independent and the $\mathrm{FEV}_{1}$ values as the dependent variable.

\section{Results}

The study comprises 68 students and 39 cotton mill workers participating in 23 cardroom experiments. The vertical elutriator dust levels in the experiments ranged from 0.46 to $6.87 \mathrm{mg} / \mathrm{m}^{3}$ and the airborne endotoxin levels ranged from 0.08 to $12.06 \mu \mathrm{g} / \mathrm{m}^{3}$. The correlation between the vertical elutriator dust and airborne endotoxin was high $\left(r_{x y}=0.77, p\right.$ $<0.001$ ).

The average $\mathrm{FEV}_{1}$ change among 15 non-exposed students was -0.3 (SD \pm 2.86$)$ with individual changes from $+8 \%$ to $-3 \%$. The relation between the individual $\mathrm{FEV}_{1}$ decrease over the shift and exposure was significant for both dust $\left(r_{x y}=0 \cdot 31, p\right.$ $<0.01)$ and endotoxin $\left(r_{x y}=0.25, p<0.01\right)$.

At a given exposure level, certain individuals showed a pronounced decrease in $\mathrm{FEV}_{1}$ and others had no reaction at all. To minimise the individual variations, average $\triangle \mathrm{FEV}_{1}$ values were calculated for groups consisting of three or more subjects. Three groups of workers did not fulfil this requirement and the results from 11 workers were omitted. These averages were calculated for students, nonsmoking workers, and smoking workers. The results from these calculations are shown in tables 2 and 3 and illustrated in figs 1 and 2 . It can be seen that the reactions among non-smoking students and nonsmoking workers differed from those among smoking workers.

There was no significant correlation between the exposure data and the group average $\triangle F E V_{1}$ in the 20 cardroom experiments but if smoking habits were kept as a constant variable the correlations between the average $\triangle F E V_{1}$ and dust and endotoxin did become significant, $\mathrm{p}<0.01$ and $\mathrm{p}<0.05$ respectively. The correlation between dust and average $\triangle$ FEV $_{1}$ for the students was $r_{x y}=-0.86(p<0.001)$ 
Table 2 Exposure data and group average $\triangle F E V$, and PMN-index over the shift for non-smoking students. Dust and endotoxin exposure represent mean values from two or three vertical elutriators

\begin{tabular}{|c|c|c|c|c|c|c|c|c|c|}
\hline \multicolumn{2}{|c|}{ Dust $\left(\mathrm{mg} / \mathrm{m}^{3}\right)$} & \multicolumn{2}{|c|}{ Endotoxin $\left(\mu \mathrm{g} / \mathrm{m}^{3}\right)$} & $\underset{N o}{\triangle F E V, \%}$ & Mean & $S D$ & \multicolumn{2}{|c|}{$\triangle P M N$-index } & $S D$ \\
\hline $\begin{array}{l}0.63 \\
1.71 \\
1.51 \\
3 \cdot 18 \\
4.02 \\
2.42 \\
0.73 \\
1 \cdot 19 \\
0.77 \\
1.71 \\
1.79 \\
6.87 \\
1.30\end{array}$ & $\begin{array}{l}0 \cdot 30 \\
0.52 \\
0 \cdot 34 \\
0 \cdot 17 \\
0 \cdot 18 \\
0 \cdot 20 \\
0 \cdot 23 \\
0 \cdot 10 \\
0 \cdot 32 \\
0 \cdot 27 \\
0 \cdot 11 \\
0 \cdot 19 \\
0 \cdot 16\end{array}$ & $\begin{array}{r}0.50 \\
2.74 \\
0.68 \\
3.90 \\
3.60 \\
0.50 \\
0.61 \\
1.82 \\
0.76 \\
0.60 \\
0.61 \\
12.06 \\
1.95\end{array}$ & $\begin{array}{l}0 \cdot 21 \\
0.10 \\
0 \cdot 02 \\
0 \cdot 12 \\
0 \cdot 17 \\
0 \cdot 01 \\
0 \cdot 26 \\
0 \cdot 06 \\
0 \cdot 28 \\
0 \cdot 24 \\
0 \cdot 26 \\
3 \cdot 93 \\
0 \cdot 10\end{array}$ & $\begin{array}{l}7 \\
6 \\
5 \\
6 \\
6 \\
5 \\
3 \\
3 \\
5 \\
4 \\
6 \\
6 \\
6\end{array}$ & $\begin{array}{r}-0.3 \\
-5.2 \\
-5.4 \\
-9.8 \\
-7.3 \\
-9.0 \\
-2.7 \\
0.0 \\
-3.4 \\
-2.8 \\
-2.3 \\
-12.8 \\
-4.0\end{array}$ & $\begin{array}{l}2.3 \\
5.1 \\
4.0 \\
5.8 \\
3.9 \\
5.8 \\
2.9 \\
1.0 \\
2.5 \\
3.3 \\
3.7 \\
6.9 \\
1.8\end{array}$ & $\begin{array}{l}7 \\
5 \\
5 \\
6 \\
6 \\
5 \\
3 \\
3 \\
5 \\
2 \\
3 \\
2 \\
0\end{array}$ & $\begin{array}{r}1.8 \\
0.3 \\
-0.6 \\
1.1 \\
0.2 \\
0.3 \\
- \\
- \\
0.4 \\
-3.4 \\
-0.8 \\
0.8 \\
-\end{array}$ & $\begin{array}{l}4 \cdot 2 \\
4 \cdot 8 \\
1 \cdot 7 \\
1 \cdot 2 \\
3 \cdot 1 \\
1 \cdot 7 \\
- \\
2 \cdot 1 \\
2 \cdot 0 \\
0 \cdot 6 \\
1 \cdot 0 \\
-\end{array}$ \\
\hline
\end{tabular}

- Indicates results not available.

Table 3 Exposure data and group average $\triangle F E V_{1}$ and $P M N$-index over the shift for workers. Dust and endotoxin exposure represent mean values from two or three vertical elutriators

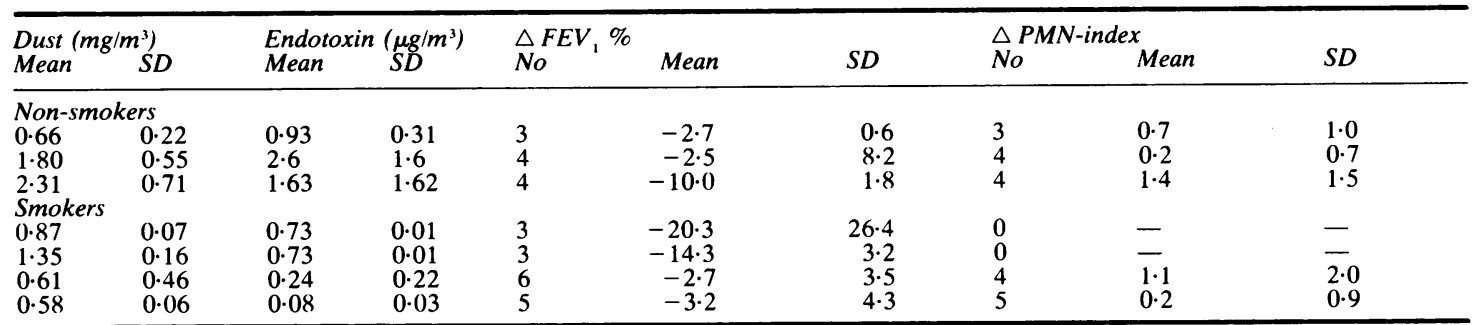

- Indicates results not available.

and between endotoxin and $\triangle \mathrm{FEV}_{1}, \mathrm{r}_{\mathrm{xy}}=-0.65$ (p $<0.02$ ).

Regarding smoking workers, the FEV, reactions were more pronounced at the same levels of dust and endotoxin than the reaction among nonsmoking workers and students. The correlation between the dust levels and the group average FEV $_{1}$ decrease was $r_{x y}=-0.72(p>0.05)$ and between endotoxin and the group average $F E V_{1}$ decrease $r_{x y}$ $=-0.86(p>0.05)$. The increased reaction was

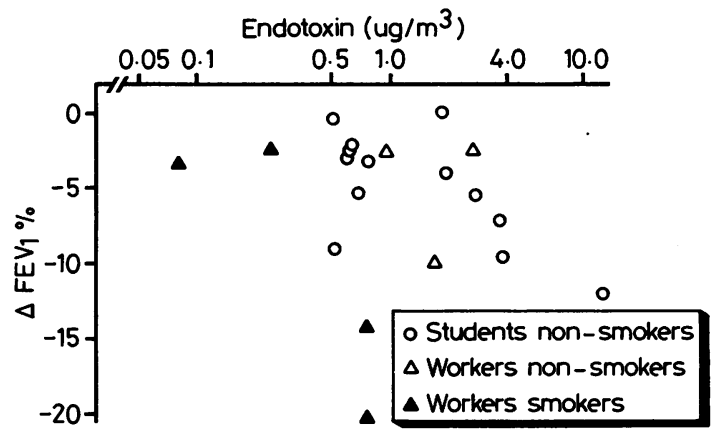

Fig 1 Relation between group average FEV, change over shift and endotoxin exposure. mostly caused by a few individuals in each group who showed pronounced reactions. Even if those participants were excluded, however, the reactions among the remaining smokers were more pronounced than among non-smokers.

Table 4 shows the amounts of airborne dust and

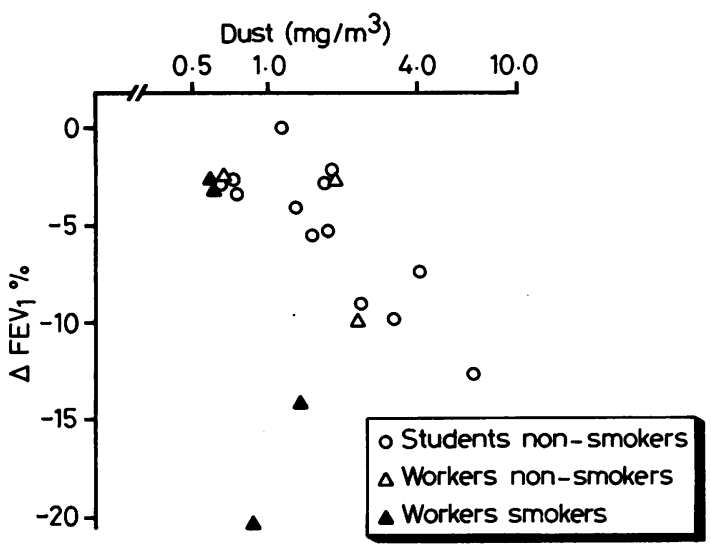

Fig 2 Relation between group average FEV ${ }_{1}$ change over shift and dust exposure. 
Table 4 Airborne dust $\left(\mathrm{mg} / \mathrm{m}^{3}\right)$ and endotoxin $\left(\mu \mathrm{g} / \mathrm{m}^{3}\right)$ levels at $0 \%, 2 \cdot 5 \%$, and $5 \%$ decrease in group average $\triangle F E V$, over shift

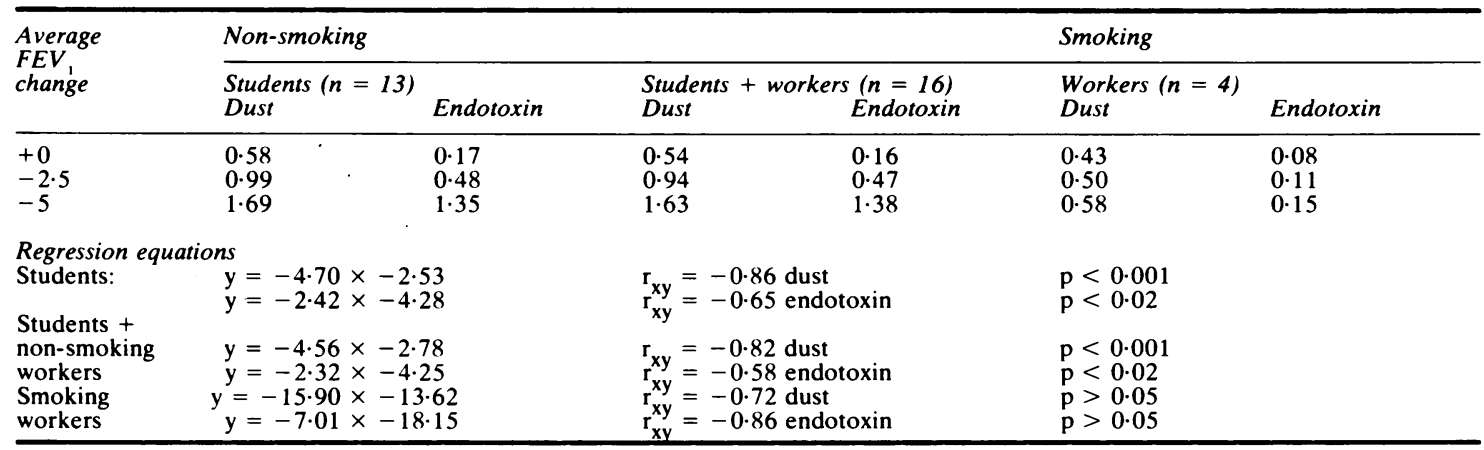

Table 5 Exposure data and group average $\triangle F E V_{1}$ and $P M N$-index over the shift in workers exposed to normal and washed cotton in two cardroom experiments. Dust and endotoxin represent mean values from two or three vertical elutriators

\begin{tabular}{|c|c|c|c|c|c|c|c|}
\hline & $\begin{array}{l}\text { Dust }\left(m g / m^{3}\right) \\
\text { Mean }\end{array}$ & $S D$ & $\begin{array}{l}\text { Endotoxin }\left(\mu \mathrm{g} / \mathrm{m}^{3}\right) \\
\text { Mean }\end{array}$ & $S D$ & $\underset{N o}{\triangle F E V_{1} \%}$ & Mean & $S D$ \\
\hline $\begin{array}{l}\text { Non-smokers } \\
\text { Washed } \\
\text { Normal }\end{array}$ & $\begin{array}{l}0.38 \\
0.66\end{array}$ & $\begin{array}{l}0.09 \\
0.22\end{array}$ & $\begin{array}{l}0.03 \\
0.93\end{array}$ & $\begin{array}{l}0.007 \\
0.31\end{array}$ & $\begin{array}{l}3 \\
3\end{array}$ & $\begin{array}{l}-2 \cdot 3 \\
-2 \cdot 7\end{array}$ & $\begin{array}{l}4 \cdot 2 \\
0.6\end{array}$ \\
\hline $\begin{array}{l}\text { Smokers } \\
\text { Washed } \\
\text { Normal } \\
\text { Washed } \\
\text { Normal }\end{array}$ & $\begin{array}{l}0.71 \\
0.87 \\
2.06 \\
1.35\end{array}$ & $\begin{array}{l}0.14 \\
0.07 \\
0.08 \\
0 \cdot 16\end{array}$ & $\begin{array}{l}0.14 \\
0.73 \\
0.18 \\
0.73\end{array}$ & $\begin{array}{l}0.00 \\
0.01 \\
0.01 \\
0.01\end{array}$ & $\begin{array}{l}3 \\
3 \\
3 \\
3\end{array}$ & $\begin{array}{r}-13 \cdot 3 \\
-20 \cdot 3 \\
-8 \cdot 3 \\
-14 \cdot 3\end{array}$ & $\begin{array}{r}5 \cdot 1 \\
26 \cdot 4 \\
3 \cdot 2 \\
3 \cdot 2\end{array}$ \\
\hline
\end{tabular}

endotoxin where no reduction in $\mathrm{FEV}_{1}$ occurred and where the average decrease was $2.5 \%$ and $5 \%$. The exposure threshold level for a zero reaction was about the same for students and smoking workers with respect to dust but for airborne endotoxin the threshold for smoking workers was lower than for students. The same pattern regarding endotoxin was found for a $2.5 \%$ or $5 \%$ reduction of $\mathrm{FEV}_{1}$.

Table 5 shows the results from the experiments with washed cotton. When the smoking workers carded normal cotton, the dust level was about the same or lower than when they carded washed cotton. The endotoxin levels were about $80 \%$ lower when washed cotton was carded and the group average $\mathrm{FEV}_{1}$ reactions was also lower.

The correlations between the change in $\mathrm{FEV}_{1}$ and the PMN-index and between the change in PMNindex and exposure data were not significant. Nevertheless, the PMN-index decreased in the experiments where no exposure took place whereas it increased in seven of the ten experiments with exposure to cotton dust.

The correlation between endotoxin exposure and a fever reaction later the same evening was $r_{x y}=$ $0.60(p>0.05)$ taking into account only eight cardroom experiments where $80 \%$ of the students that took part gave an answer in the questionnaire. In the three cardroom experiments where the endotoxin exposure levels were above $3 \mu \mathrm{g} / \mathrm{m}^{3}, 80-100 \%$ of the students reported fever in the evening and they all reported symptoms of chest tightness or cough at the end to the cardroom experiment.

\section{Discussion}

The exposure in these experiments was expressed using vertical elutriator filters that sample the respirable portion of the dust as opposed to the total dust or total dust less fly.? The dose levels were expressed as the average of two or three vertical elutriator samples in different parts of the cardroom. A better description of the dose could have been obtained by using personal samplers with cyclones or vertical elutriators, but this equipment was not available when the experiments started. As the subjects moved around in the cardroom during the four hour working period, the stationary vertical elutriator values were considered to give a sufficiently precise description of the individual's dose.

A dose response relationship was shown between the average FEV 1 decrement over the working shift and the amount of airborne dust or endotoxin. The 
threshold for a $5 \%$ decrease in $\mathrm{FEV}_{1}$ among nonsmoking students and workers was about $1.63 \mathrm{mg}$ dust $/ \mathrm{m}^{3}$ and for smoking workers $0.58 \mathrm{mg} / \mathrm{m}^{3}$. Boehlecke exposed a group of 30 subjects to different types of cotton with mean dust concentrations ranging from 0.04 to $0.98 \mathrm{mg} / \mathrm{m}^{3}$." The subjects were selected from those who reacted with at least a $5 \%$ change in $\mathrm{FEV}$, when exposed to $1 \mathrm{mg} / \mathrm{m}^{3}$ of respirable cotton dust. The mean decrease in FEV in the 11 experiments reported ranged between $1 \%$ and $2 \%$ of the baseline value. The threshold exposure giving a mean decrease in $\mathrm{FEV}_{1}$ of about $5 \%$ could be estimated from the fitted regression equations in Boehlecke's study to be $0.76 \mathrm{mg} / \mathrm{m}^{3}$. The discrepancy in threshold levels between this study and the present investigation regarding the value for a $5 \% \mathrm{FEV}_{1}$ reduction among subjects not previously exposed to cotton dust is probably due to the populations studied. Boehlecke's study was made with subjects selected because of their airway reactivity. The present investigation was made with subjects without selection regarding airway reactivity.

Merchant $e t$ al found a $5 \%$ decrease in FEV ${ }_{1}$ at an exposure level of $0.62 \mathrm{mg} / \mathrm{m}^{3}$ (measured with a cyclone separator described by Lynch) in 12 cotton workers exposed to strict low middling cotton in an exposure chamber. ${ }^{12}$ Among these workers seven were smokers, and the group was selected because they had exhibited decreased expiratory flow rates during cotton dust exposures in earlier studies. The exposure value corresponding to a $5 \%$ decrease in that study is similar to the value for workers in the present study.

The observations on smoking workers in the present study comprise only four data points and the conclusion regarding a different dose response relationship is not strong. Nevertheless, a larger decrease in FEV, was observed among the groups of smoking workers than among the non-smoking workers or the students at the same exposure levels. The large average decrease in smoking groups was partly caused by certain individuals with a large reaction. Among non-smoking workers these extreme reactions were not observed. Similar differences between individuals have been observed in another study where smoking cotton mill workers are exposed to dust from cotton from different geographic locations (R Rylander et al, submitted for publication). This suggests that in certain individuals cigarette smoke may predispose to a more pronounced airway reaction to cotton dust exposure.

The conclusion agrees with results from earlier studies, in which a stronger reaction was found among smokers than among non-smokers. Merchant et al fitted dose response equations to data obtained from a study on cotton mill workers in
North Carolina. ${ }^{2}$ Different relationships between dust and FEV 1 changes were found for smokers and non-smokers. In a group of cotton workers subjected to detailed respiratory function testing before and after the shift indications of larger acute and chronic effects were found among smokers. ${ }^{13}$

The presence among the students of chest tightness at high exposure levels shows that this reaction does not require a previous exposure to cotton dust over long periods. It is possible that the reaction threshold may be successively lowered with time among certain individuals. The mechanism behind this is not known.

In this study no dose response relationship was found between the change in PMN-index over the working shift and the amount of vertical elutriator dust or endotoxin. Compared with the findings when no exposure to cotton dust took place, an increase in PMN on the nasal epithelium was found in seven of the ten experiments with students and in all experiments with workers. In this respect the findings agree with previous observations by Merchant et al.$^{12}$ The dose response relationship that has been found for animal exposure ${ }^{14}$ could not be shown. The PMN-index evaluated with the method used here thus lacks the precision required to make it suitable as a response criterion for people exposed to cotton dust.

A strong correlation was found between levels of airborne dust and endotoxin. The experimental set up therefore does not lend itself to evaluate whether dust or endotoxin is the best dose descriptor. The results from the group with smoking workers or the experiment with washed cotton indicates that the $\mathrm{FEV}_{1}$ response was more strongly related to endotoxin. The washing procedure could, however, have removed other possible byssinosis producing agents from the cotton.

The presence of fever among certain of the students in the evening is similar to the "mill fever" reported among newly employed cotton workers. This is caused by the endotoxin present in the cotton dust.

The results from the experiments with washed cotton agree with previous findings by Merchant $e t$ $a^{15}$ who measured pulmonary reactions in cardroom workers who were carding cotton that had been treated in different ways. In those experiments, however, the dust level in the cardrooms was reduced to one quarter of the original value when washed cotton was used. The results thus cannot be used to determine whether the washing procedure selectively removed a particular agent from the cotton. The same deficiency is present in another report on the effect of washing cotton. ${ }^{16}$ To explore further the role of endotoxin for changes in pulmo- 
nary respiratory function, experiments should be undertaken in which subjects are exposed to different types of cotton with varying contents of endotoxin. Such studies are under way.

The experiments were performed with funds from Cotton Incorporated (agreement 77/342) and the Swedish Work Environment fund (contract 78/132). The statistical analyses were kindly performed by $\mathbf{A}$ Odén, Gothenburg, and Dr E Römer, Institute for Biological Research, Cologne.

\section{References}

' Weill H, ed. International conference on byssinosis. Chest 1981; 79:1-136S.

${ }^{2}$ Merchant JA, Lumsden JC, Kilburn KH, et al. Dose response studies in cotton textile workers. JOM 1973;15:222-30.

${ }^{3}$ Cinkotai FF, Lockwood MG, Rylander R. Airborne microorganisms and prevalence of byssinotic symptoms in cotton mills. Am Ind Hyg Assoc J 1977;38:554-9.

${ }^{4}$ Cinkotai FF, Whitaker CJ. Airborne bacteria and the prevalence of byssinotic symptoms in 21 cotton spinning mills in
Lancashire. Ann Occup Hyg 1978;21:239-50.

${ }^{5}$ Rylander R, Imbus HR, Suh MW. Bacterial contamination of cotton as an indicator of respiratory effects among cardroom workers. $\mathrm{Br}$ J Ind Med 1979;36:299-304.

- Rylander R. Bacterial toxins and etiology of byssinosis. Chest 1981;79:34-38S.

${ }^{7}$ Neefus JD, Lumsden JC, Jones MJ. Cotton dust sampling. II Vertical elutriation. Am Ind Hyg Assoc J 1977;38:394-400.

${ }^{8}$ Rylander R, Morey P. Airborne endotoxins in industries processing vegetable fibres. Am Ind Hyg Assoc J 1982;43:811-2.

${ }^{9}$ Morris JF, Koski A, Johnson LC. Spirometric standards for healthy non-smoking adults. Am Rev Respir Dis 1971;103: 57-67.

${ }^{10}$ Mantel N. Chi-square test with one degree of freedom: extensions of the Mantel-Haenszel procedure. Journal of the American Statistical Association 1963;58:690-700.

"Boehlecke B. Pulmonary function response to standard and washed cotton dust. Chapel Hill: University of North Carolina, 1981:1-47.

12 Merchant JA, Halprin GM, Hudson AR, et al. Responses to cotton dust. Arch Environ Health 1975;30:222-9.

${ }^{13}$ Haglind P, Bake B, Belin L. Is mild byssinosis associated with small airways disease? Eur J Respir Dis 1983;64:449-59.

14 Helander I, Saxen H, Salkinoja-Salonen M, Rylander R. Pulmonary toxicity of endotoxins: comparison of lipopolysaccharides from various bacterial species. Infect Immun 1982;35:528-32.

${ }^{15}$ Merchant JA, Lumsden JC, Kilburn KH, et al. Preprocessing cotton to prevent byssinosis. Br J Ind Med 1973;30:237-47.

${ }^{16}$ Brown DF, Berni RJ, Coche JB, Bragg CK. Effects of washing raw stock cotton on trash and carding dust levels and FEV, values-a pilot study. Textile Res 1979;7:679-80. 